\title{
Equatorward Pathways of Solomon Sea Water Masses and Their Modifications
}

\author{
ANGÉlique MELET AND JACQUeS VERRON \\ LEGI, UMR5519, CNRS, Université de Grenoble, Grenoble, France \\ LiOnel Gourdeau AND ARIANE Koch-LARROUY \\ LEGOS, UMR5566, IRD, CNRS, Université Paul Sabatier, Toulouse, France
}

(Manuscript received 19 August 2010, in final form 19 November 2010)

\begin{abstract}
The Solomon Sea is a key region of the southwest Pacific Ocean, connecting the thermocline subtropics to the equator via western boundary currents (WBCs). Modifications to water masses are thought to occur in this region because of the significant mixing induced by internal tides, eddies, and the WBCs. Despite their potential influence on the equatorial Pacific thermocline temperature and salinity and their related impact on the low-frequency modulation of El Niño-Southern Oscillation, modifications to water masses in the Solomon Sea have never been analyzed to our knowledge. A high-resolution model incorporating a tidal mixing parameterization was implemented to depict and analyze water mass modifications and the Solomon Sea pathways to the equator in a Lagrangian quantitative framework. The main routes from the Solomon Sea to the equatorial Pacific occur through the Vitiaz and Solomon straits, in the thermocline and intermediate layers, and mainly originate from the Solomon Sea south inflow and from the Solomon Strait itself. Water mass modifications in the model are characterized by a reduction of the vertical temperature and salinity gradients over the water column: the high salinity of upper thermocline water [Subtropical Mode Water (STMW)] is eroded and exported toward surface and deeper layers, whereas a downward heat transfer occurs over the water column. Consequently, the thermocline water temperature is cooled by $0.15^{\circ}-0.3^{\circ} \mathrm{C}$ from the Solomon Sea inflows to the equatorward outflows. This temperature modification could weaken the STMW anomalies advected by the subtropical cell and thereby diminish the potential influence of these anomalies on the tropical climate. The Solomon Sea water mass modifications can be partially explained $(\approx 60 \%)$ by strong diapycnal mixing in the Solomon Sea. As for STMW, about a third of this mixing is due to tidal mixing.
\end{abstract}

\section{Introduction}

It was hypothesized that the Pacific decadal variability is influenced by changes in the strength or water mass properties of the meridional circulation associated with the subtropical cells (STCs; McCreary and Lu 1994). The STCs are characterized by subduction in the subtropical gyres, equatorward flow at the thermocline level via both an interior pathway and low-latitude western boundary currents (LLWBCs), equatorial upwelling in the Equatorial Undercurrent (EUC), and Ekman surface return flow to the subtropics. The Pacific equatorial sea surface temperature (SST) is thus directly influenced by the upwelling of EUC water, and changes in EUC

Corresponding author address: Angélique Melet, Laboratoire des Ecoulements Géophysiques et Industriels, MEOM, BP 53 X, Grenoble CEDEX, France.

E-mail: melet@hmg.inpg.fr properties could have potential impacts on the equatorial Pacific climate and the low-frequency modulation of El Niño-Southern Oscillation (ENSO; e.g., Gu and Philander 1997; Kleeman et al. 1999; Schneider 2004; Luo et al. 2005). The South Pacific LLWBCs are seen as a major contributor to the EUC (Tsuchiya 1981; Tsuchiya et al. 1989; Blanke and Raynaud 1997; Fukumori et al. 2004). These currents transit through the Solomon Sea, which is located north of the Coral Sea and bounded on the west by New Guinea, on the east by the Solomon Island chain, and on the north by the island of New Britain (NB; Fig. 1). A double system of LLWBCs (Melet et al. 2010a, hereafter AM10) connects subtropical water to the EUC as part of the STC circulation in the Solomon Sea region through three narrow straits (Vitiaz Strait, St. George's Channel, and Solomon Strait).

The scarce available in situ observations suggest an erosion of the vertical temperature and salinity $(T-S)$ gradients of water crossing the Solomon Sea (Fig. 2). 


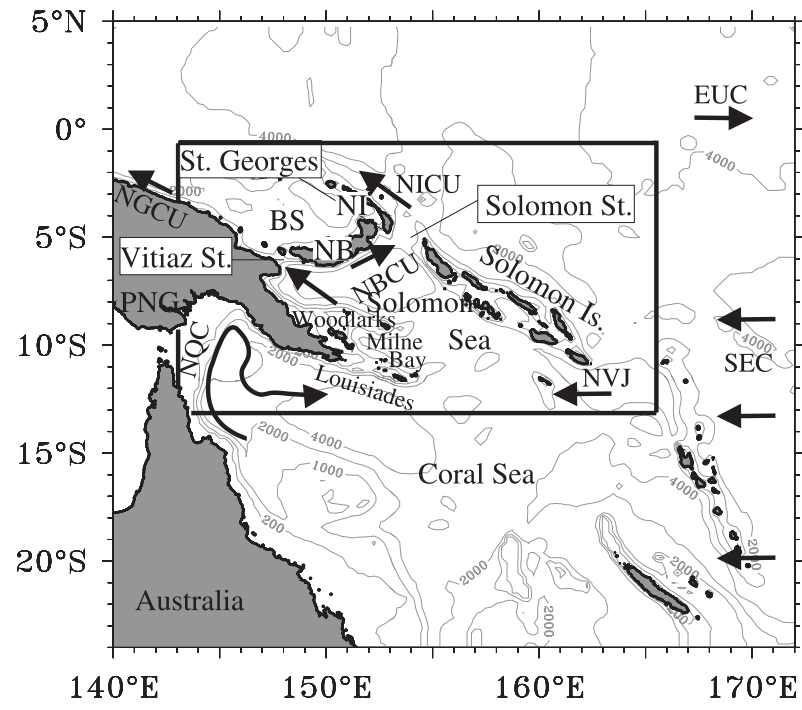

FIG. 1. Geography over the $1 / 4^{\circ}$ and $1 / 12^{\circ}$ models, with gray contours for 200-, 1000-, 2000-, 4000-, and 6000-m depths. The black rectangle delineates the domain of the $1 / 12^{\circ}$ model. The names of the main thermocline currents are indicated and listed in the text.

Different physical processes can explain modifications to the water masses of the Solomon Sea. The strong and vertically sheared WBC (AM10) may lead to instabilities. Interactions of external tides with the topography give rise to strong internal tide generation and tidal energy dissipation in the Solomon Sea, as shown by different observational (Egbert and Ray 2000) and numerical studies (Jayne and St. Laurent 2001; Niwa and Hibiya 2001; Simmons et al. 2004; Arbic et al. 2004). These processes, as well as large eddy activity such as intense permanent eddies associated with boundary currents and recirculations (Tsuchiya et al. 1989; AM10; Melet et al. 2010b), may lead to enhanced mixing (e.g., Gordon and Corry 1991; Blanke and Delecluse 1993; Niwa and Hibiya 2001) and contribute to the erosion of the $T-S$ characteristics of the thermocline water (TW), with a direct impact on the EUC temperature.

Despite its importance in understanding climate variability, few studies have focused on the Solomon Sea because of the lack of observations and the difficulty of modeling a region of such complex bathymetry. Fine et al. (1994), Sokolov and Rintoul (2000), and Qu and Lindstrom (2002) used historical data to investigate the mass field in the western South Pacific. Recently, the mean thermocline circulation in the Solomon Sea and its annual cycle have been analyzed using a numerical simulation (AM10) and SADCP data (Cravatte et al. 2011). However, to our knowledge, no study has yet focused on the modifications to Solomon Sea water masses. In this context, the Solomon Sea study based on modeling and the collection and analysis of observations is a key aspect

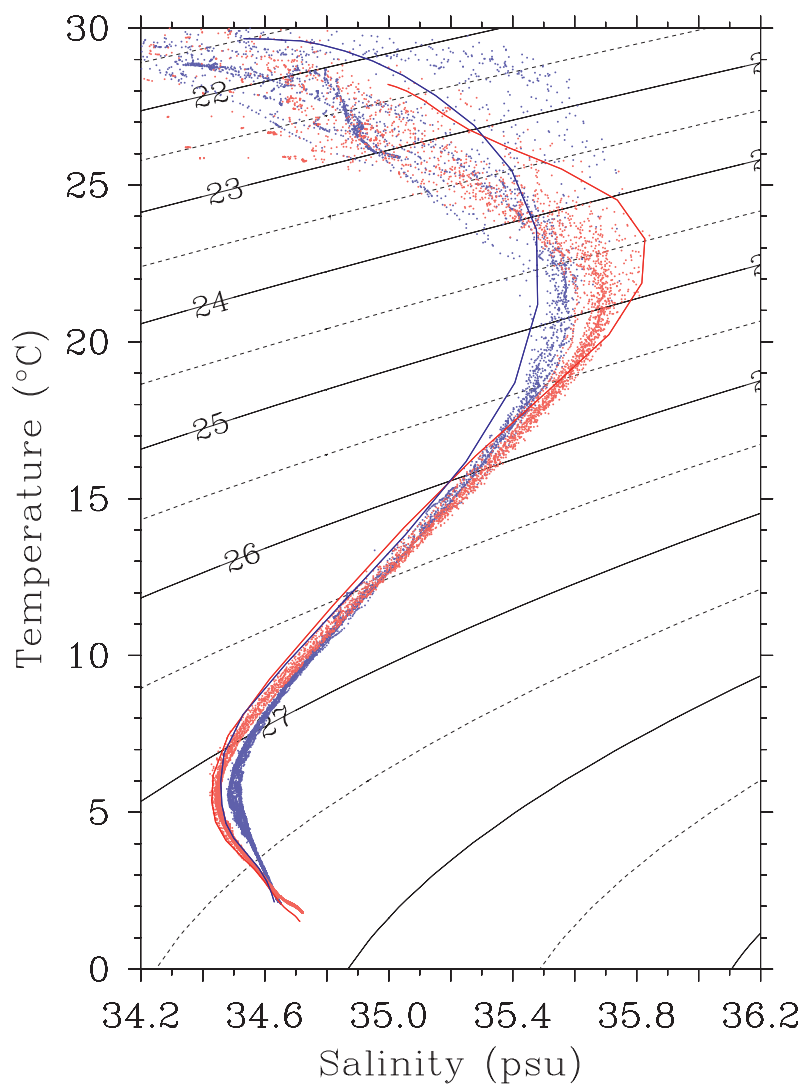

FIG. 2. The $T-S$ diagrams from the Coriolis database (dots) and from the model (line) upstream (red; $11.5^{\circ}-13^{\circ} \mathrm{S}, 147^{\circ}-153^{\circ} \mathrm{E}$ ) and downstream (blue; $3^{\circ}-5^{\circ} \mathrm{S}, 143^{\circ}-147^{\circ} \mathrm{E}$ ) of the Solomon Sea. Only profiles flagged as "good data" were extracted from the Coriolis database, from 1 Jan 1950 to 1 Jun 2010.

of the Climate Variability and Predictability (CLIVAR) Southwest Pacific Ocean Circulation and Climate Experiment (SPICE) program (Ganachaud et al. 2007), which provides a framework for the present study.

The objectives of this study are to diagnose climatological equatorward pathways of Solomon Sea water and modifications in the water masses, especially in the thermocline layer, as a first step to understanding how such changes in the water mass properties could influence the equatorial Pacific climate and ENSO. Because observational diagnoses are currently hampered by the scarcity of in situ data, our approach is mainly based on a quantitative Lagrangian method applied on modeled Eulerian fields. To handle the complex bathymetry and resolve the narrow straits connecting the Solomon Sea to the equator in a numerical model, we implemented a high-resolution model $\left(1 / 12^{\circ}\right)$ over the Solomon Sea. A tidal mixing parameterization was used to represent the mixing associated with internal tides.

The paper is organized as follows: First, the methodology is presented in section 2 . Then, the representation 
of the water masses in the model is assessed using available observational data in section 3 . In section 4 , the different routes followed by Solomon Sea water to join the equatorial Pacific are diagnosed, as well as their transit time. Modifications modeled in the Solomon Sea water masses are analyzed in section 5 , as well as the relative importance of diapycnal mixing. Finally, section 6 provides a summary and some concluding remarks.

\section{Methodology}

\section{a. Model}

Model configurations are described in detail in AM10; we only review their main characteristics in this section. The high-resolution primitive equations model $\left(1 / 12^{\circ}\right)$ of the Solomon Sea used in this study is interactively nested in a $14^{\circ}$ regional model of the tropical southwest Pacific (Fig. 1), which is itself embedded offline (open boundaries) in a $1 / 4^{\circ}$ OGCM. All three models are based on the oceanic component of the Nucleus for European Modelling of the Ocean (NEMO) system, the Ocean Parallelisé (OPA) OGCM (Madec 2008). The vertical coordinate is geopotential with 46 prescribed levels ranging from the surface to a depth of $5875 \mathrm{~m}(6-15 \mathrm{~m}$ vertical resolution in the upper $100 \mathrm{~m}$ ). In addition, the bathymetry of the $1 / 12^{\circ}$ model has been carefully checked to ensure that it is realistic.

The diffusion of tracers is performed along isopycnal surfaces through a Laplacian operator, whereas the dissipation of momentum is achieved through a bi-Laplacian operator along geopotential surfaces. The vertical eddy viscosity and diffusivity coefficients are computed from a turbulent closure model (TKE; Blanke and Delecluse 1993), with background diffusivity coefficients of $0.1 \mathrm{~cm}^{2} \mathrm{~s}^{-1}$ for tracers. In addition, a tidal dissipation parameterization has been used in our nonhydrostatic model. In the semi-enclosed Solomon Sea, we applied the parameterization recently developed for the Indonesian seas by Koch-Larrouy et al. (2007), based on the similarities observed between the Solomon and Indonesian archipelagoes (latitude, stratification, and topography). In this formulation, internal tides are assumed to be trapped and entirely dissipated in the semi-enclosed basins where they are generated. The vertical distribution of the dissipation was found to reach a maximum in the thermocline. This parameterization was validated with observations (KochLarrouy et al. 2007, 2010). Outside the Solomon Sea, in the open basins of the domain used in this study, we applied the formulation proposed by Jayne and St. Laurent (2001) and introduced in NEMO-OPA by Bessières et al. (2008). In this formulation, $1 / 3$ of the internal tidal energy is dissipated at the bottom of the ocean directly after internal tides generation (Jayne and St. Laurent 2001). The remaining $2 / 3$ of the energy is assumed to radiate and has still to be dissipated. To quantify the impact of tidal parameterization on water mass modifications, a sensitivity experiment, called NOTIDE, was run without tidal mixing parameterization.

The regional and fine-grid models are forced in the same way, with the datasets used to force the global model. Atmospheric fluxes of momentum, heat, and freshwater are diagnosed through classical bulk formulas (Large and Yeager 2009). Realistic winds and atmospheric temperature and humidity are provided by the 40-yr European Centre for Medium-Range Weather Forecasts (ECMWF) Re-Analysis (ERA-40). Precipitation and radiations are provided by the Common Ocean-ice Reference Experiments (CORE) dataset (Yeager and Large 2004). Regional models were initialized with the climatological mass field of Levitus et al. (1998) and were integrated over the 1984-98 period. An initial period of $2 \mathrm{yr}$ was used for the adjustment of the regional models so that the 1986-98 period can be used in this study. Outputs consisted of daily means for both regional models.

\section{b. Lagrangian tracers}

Solomon Sea waters pass mainly through the Vitiaz Strait, St. George's Channel, and the Solomon Strait (Fig. 1) to connect with the equatorial Pacific. Thus, a numerical particles Lagrangian experiment was performed for each of these straits to identify the different Solomon Sea routes connecting with the equatorial Pacific.

The Lagrangian analysis (ARIANE algorithm, available online at http://stockage.univ-brest.fr/ grima/Ariane/; Blanke and Raynaud 1997; Blanke et al. 1999) was performed offline using the daily averaged modeled velocity fields. Because it only considers the advection and streamlines, the particle tracing method does not explicitly calculate diffusion along its trajectories. However, the particle tracing method was also applied on the daily averaged $T-S$ fields generated by the model that resolves the full $T-S$ evolution, including their modifications through mixing and forcing terms. Thus, the mixing of water mass properties was provided implicitly by the along-trajectory changes in these properties, and water mass modifications could be determined and analyzed through this Lagrangian method (Blanke et al. 1999).

Each grid cell corresponding to an outflow of the strait section under consideration was seeded by a particle every day. As particles were allowed to be integrated backward in time up to $4 \mathrm{yr}$, and, because the exploitable simulation period is 1986-98, particles were seeded for the 1990-98 period. As a result, more than 1103000 particle trajectories were computed from the Solomon Strait, 450000 were computed from the Vitiaz Strait, and 214000 were computed from St. George's Channel. Backward integration 
TABLE 1. Definition of water masses and their associated colors in Figs. 8 and 9. Note that TW includes UTW, MAWX, and MTW, whereas SW includes upper surface water (USW) and LSW.

\begin{tabular}{|c|c|c|c|}
\hline Surface Water & SW & & \\
\hline Upper Surface Water & USW & $\sigma_{0}<22.3$ & Light green \\
\hline Lower Surface Water & LSW & $22.3<\sigma_{0}<23.3$ & Green \\
\hline Upper part of thermocline water & TW & & \\
\hline Upper thermocline water & UTW & $23.3<\sigma_{0}<24.3$ & Light blue \\
\hline Maximum salinity water & MAXW & $24.3<\sigma_{0}<24.7$ & Cyan \\
\hline Midthermocline water & MTW & $24.7<\sigma_{0}<25.7$ & Blue \\
\hline Lower thermocline water & LTW & $25.7<\sigma_{0}<26.7$ & Purple \\
\hline Immediate water & IW & $26.7<\sigma_{0}<27.5$ & Orange \\
\hline Deep water & DW & $27.5<\sigma_{0}$ & Red \\
\hline
\end{tabular}

was performed until particles reached one of the receptive sections (see Fig. 5 for the section locations).

A fixed elementary transport is associated with each particle so that a Lagrangian transport can be computed between the departure and arrival sections from the individual particle trajectories. Thus, this mass-preserving method allows quantitative diagnoses describing the total Eulerian streamfunction and enables us to separate the routes taken by particles to join different sections. Note that, although the integration was performed backward, we will use a forward framework terminology in the following sections, where the final state refers to the state at the Solomon Sea northern strait.

\section{Validation}

Validation of the Solomon Sea thermocline circulation, transports, and temperature field is provided for the NOTIDE run in AM10. The present run with tidal parameterization, called TIDE, does not exhibit significant differences with regard to the main dynamical features. In this section, we use available observations to evaluate the modeled representation of the water masses.

The modeled $T-S$ profiles upstream and downstream of the Solomon Sea are first illustrated and compared to observations from the Coriolis database (Fig. 2). Solomon Sea waters display a salt minimum in the intermediate layer, characteristic of the Antarctic Intermediate Water (AAIW; Sokolov and Rintoul 2000), and a salt maximum in the upper part of the thermocline, characteristic of the Subtropical Mode Water (STMW; Sokolov and Rintoul 2000; Holbrook and Maharaj 2008) formed in the center of the southeast Pacific subtropical gyre and transported westward by the South Equatorial Current (SEC). The TIDE mean modeled water masses are in agreement with the observations, although they are warmer and saltier than those observed above $\sigma_{0}=25.5 \mathrm{~kg} \mathrm{~m}^{-3}$, whereas they are colder and fresher below.

Let us now focus on the upper thermocline (defined here as the layer from $\sigma_{0}=23.3 \mathrm{~kg} \mathrm{~m}^{-3}$ to $\sigma_{0}=$ $25.7 \mathrm{~kg} \mathrm{~m}^{-3}$; Table 1), which is the most relevant part of the water column regarding the impact of $T-S$ modifications on the EUC. The tidal mixing parameterization introduced in our model inside the Solomon Sea enhances vertical diffusivity in the thermocline outside the WBC region and notably in the regions of high energy transfer from barotropic to baroclinic tides: along the two ridges extending from the Louisiade and Woodlark archipelagoes (Fig. 1) and around the Solomon Strait (Fig. 3). The modeled $T-S$ fields with and without tidal parameterization are compared to the Commonwealth Scientific and Industrial Research Organisation (CSIRO) Atlas of Regional Seas (CARS) climatology (Ridgway et al. 2002). Note that, because CARS only provides a relatively coarse resolution and is based on the scarce data available for the Solomon Sea, some uncertainties exist on the reliability of its water mass properties. Thus, comparisons of our modeling results with CARS are to be taken with some caution. In the thermocline layer, both the observed thermocline temperature (not shown) and the salinity of the CARS climatology are more realistically reproduced in the TIDE experiment (Fig. 4) than in the NOTIDE experiment. South of the Solomon Sea, the salt maximum corresponding to the STMW advected by the North Vanuatu Jet (NVJ)-SEC observed in CARS is reproduced by both the TIDE and the NOTIDE solutions, even if a salty bias of about 0.1 psu may be noted in the model. The salty waters are then advected by the New Guinea Coastal Undercurrent (NGCU) and the New Britain Coastal Undercurrent (NBCU) (Fig. 1) in the Solomon Sea in both the model and CARS. In addition, a meridional salinity gradient east of the islands chain composed of the Solomon Islands and New Ireland (NI) is observed both in CARS and in our model. The tidal parameterization results in a weakening of salinities in and downstream of the Solomon Sea, which is in better agreement with observations. Indeed, the zonal salinity gradient observed in CARS across the Solomon Islands (Fig. 1) is better reproduced in TIDE, although it is a little stronger than in CARS. Upstream of the Solomon Sea, the salt minima observed in CARS in the Bismarck Sea and along the northern coast of Papua New Guinea (PNG) (Fig. 1) are also better reproduced in TIDE. As a result, 


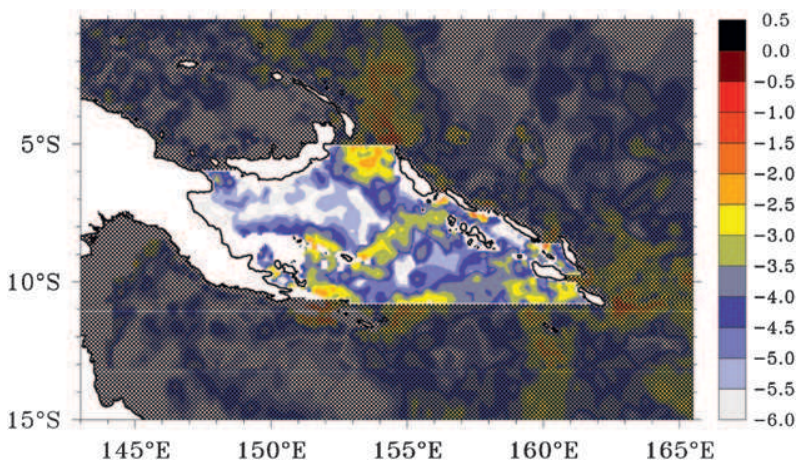

FIG. 3. Vertical diffusivity resulting from internal tide breaking averaged over the $\sigma_{0}=24.3 \mathrm{~kg} \mathrm{~m}^{-3}$ to $\sigma_{0}=24.7 \mathrm{~kg} \mathrm{~m}^{-3}$ layer (logarithm scale). The region where the thermocline enhanced tidal mixing parameterization is applied is not hatched.

both the CARS thermocline vertically averaged temperature (not shown) and salinity are fairly well reproduced by the model with the tidal mixing parameterization (Figs. 4a,b).

The agreement between our simulation and observations both in terms of water masses properties (Figs. 2, 4) and circulation (AM10) allows us to analyze water mass pathways and modifications in the Solomon Sea using our model with some confidence in the robustness of our results.

\section{Water masses routes}

In this section, the different routes followed by Solomon Sea water to join the equatorial Pacific are diagnosed, as well as their transit times.

\section{a. Pathways from Solomon Sea inflows to Solomon Sea outflows}

\section{1) BAROTROPIC STREAMFUNCTION TO EACH NORTHERN STRAIT}

In our model, for the 1990-98 period, Solomon Sea mean top-to-bottom outflows mostly occur through the Vitiaz Strait $\left[16.0 \mathrm{~Sv}\left(1 \mathrm{~Sv} \equiv 10^{6} \mathrm{~m}^{3} \mathrm{~s}^{-1}\right)\right]$ and the Solomon Strait (12.0 Sv). St. George's Channel only accounts for a small part of the Solomon Sea equatorward outflows, with $2.5 \mathrm{~Sv}$ (Fig. 5).

The top-to-bottom Vitiaz Strait outflow of $16.0 \mathrm{~Sv}$ is dominated by the transport associated with the waters originating from the Solomon Sea south inflow (14.2 Sv, representing $89 \%$ of the total outflow). Solomon Strait $(1.2 \mathrm{~Sv}, 7.5 \%)$ and Vitiaz Strait recirculations (0.2 Sv, $1.5 \%)$ only represent minor Solomon Sea pathways leading to the Vitiaz Strait outflow (Fig. 5a). The top-to-bottom St. George's Channel outflow of $2.5 \mathrm{~Sv}$ is also dominated by water originating from the Solomon Sea south inflow (1.7 Sv, 68\%), but the contributions of water originating $\begin{array}{llllllllll}35.1 & 35.2 & 35.3 & 35.4 & 35.5 & 35.6 & 35.7 & 35.8 & 35.9 & 36.0\end{array}$
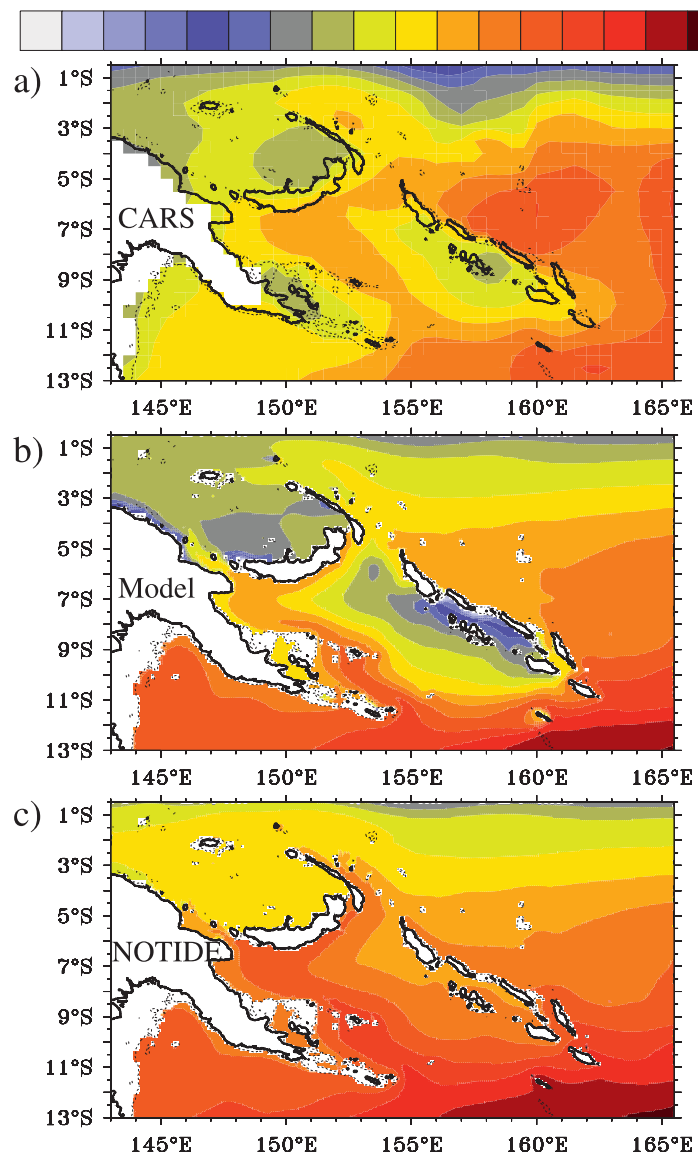

FIG. 4. Salinity averaged over the $\sigma_{0}=23.3 \mathrm{~kg} \mathrm{~m}^{-3}$ to $\sigma_{0}=$ $25.7 \mathrm{~kg} \mathrm{~m}^{-3}$ layer. Units are in psu. (a) CARS climatology, (b) TIDE experiment, and (c) NOTIDE experiment.

from the Solomon Strait (0.6 Sv, 22\%) and St. George's recirculations $(0.2 \mathrm{~Sv}, 9 \%)$ are stronger than for the Vitiaz Strait outflow (Fig. 5b). Unlike the Vitiaz Strait and St. George's Channel outflows, the Solomon Strait outflow of $12.0 \mathrm{~Sv}$ is not dominated by the transport associated with the south inflow route. Indeed, 57\% (6.6 Sv) of the total transport comes from Solomon Strait recirculations, 39\% (4.5 Sv) comes from the Solomon Sea south inflow, and 3\% (0.3 Sv) comes from St. George's Channel (Fig. 5c).

Waters joining the northern straits from the south inflow are advected by the Solomon Sea main WBC, composed of the New Guinea Coastal Current (NGCC) in the surface layer and of the NGCU in the subsurface layer, to the Vitiaz Strait and then by the NBCU to St. George's Channel and the Solomon Strait (Figs. 1, 5). More precisely, they enter the Solomon Sea along the PNG coast $\left(152^{\circ}-154^{\circ} \mathrm{E}\right)$, flow through and around Milne Bay, and then flow along the Woodlarks and PNG main coast until they reach the Vitiaz Strait (Fig. 5). Waters 

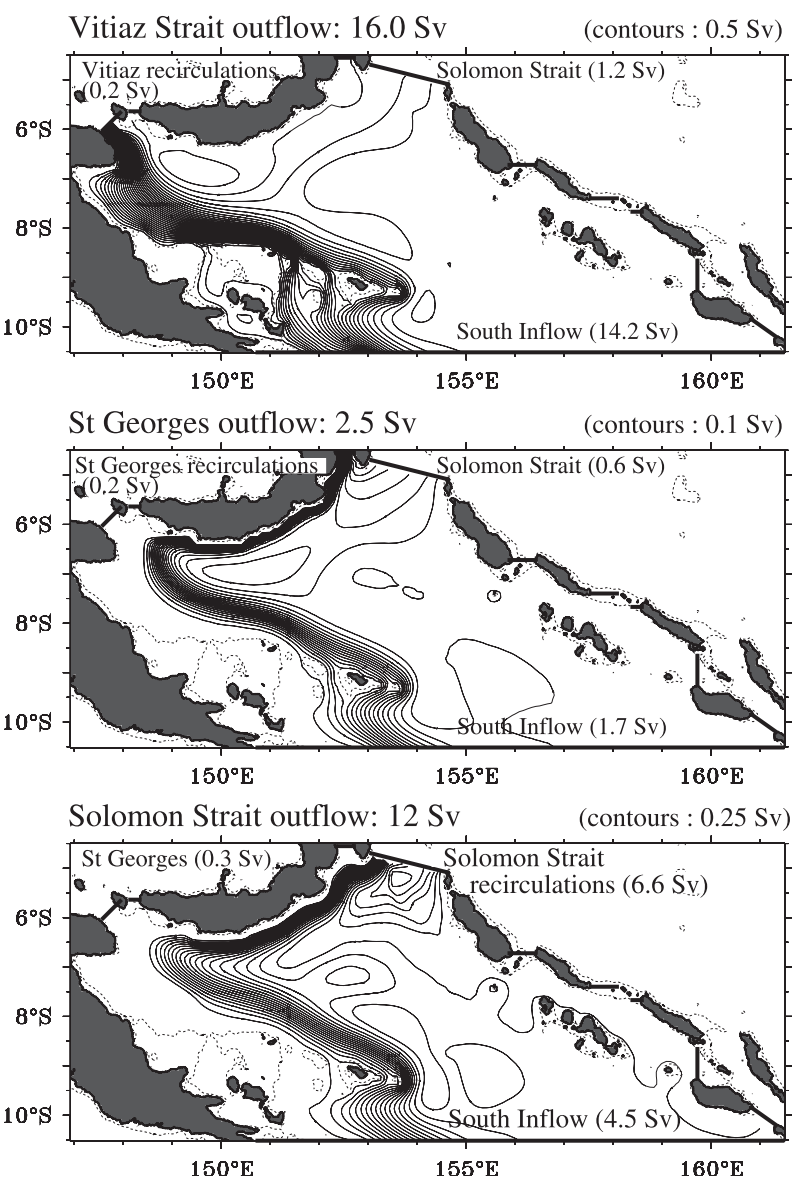

FIG. 5. Barotropic streamfunction for Solomon Sea waters outflowing through (a) the Vitiaz Strait, (b) St. George's Channel, and (c) the Solomon Strait. Contours are in Sv and their spacing is specified for each panel. The top-to-bottom transports issuing from the principal Solomon Sea inflows are listed in parentheses in each panel, and the top-to-bottom strait outflow is indicated at the top of each panel. Differences of transport observed between the total outflow through the northern straits and the sum of the transports along the principal routes listed in each panel are accounted for particles that "evaporated" at the surface, originated from the Solomon Islands straits, or have not reached a section after $4 \mathrm{yr}$ of backward integration.

joining St. George's Channel and the Solomon Strait enter the Solomon Sea farther east $\left(153^{\circ}-155^{\circ} \mathrm{E}\right)$ and flow around Milne Bay in the eastern part of the NGCU until they reach the western New Britain coast and form the NBCU. Then, waters are advected along New Britain by the inshore portion of the NBCU to St. George's Channel, whereas the offshore portion of the current flows through the Solomon Strait (Fig. 5).

The pathways from the Solomon to Vitiaz straits are quite direct, with waters crossing the central Solomon Sea to join the NGCU north of the Woodlarks before being advected to the Vitiaz Strait. As for the Solomon Strait pathways to St. George's Channel and the Solomon Strait itself, they involve waters originating from the southern part of Solomon Strait, which recirculate to join the NBCU before exiting the Solomon Sea (Fig. 5).

\section{2) 3D STRUCTURE OF THE PATHWAYS}

To provide a 3D structure of the flow, the water column is divided into density classes, as defined in Table 1. The surface waters (SW) are defined as the water above $\sigma_{0}=23.3 \mathrm{~kg} \mathrm{~m}^{-3}$, which is the lighter isopycnal surface that does not outcrop in the Solomon Sea during the 198698 period (not shown). Thermocline waters are encompassed between $\sigma_{0}=23.3 \mathrm{~kg} \mathrm{~m}^{-3}$ and $\sigma_{0}=26.7 \mathrm{~kg} \mathrm{~m}^{-3}$. The three upper layers of the thermocline waters defined in Table 1 [upper thermocline water (UTW), maximum salinity water (MAXW), and midthermocline water (MTW)] are grouped into the upper part of the TW and will be the focus of our attention in the following sections for two reasons. First, they contain the salty water (Fig. 2) characteristic of the STMW (especially true for MAXW), which is advected by the South Pacific STC from the subtropics to the equator (e.g., McCreary and $\mathrm{Lu}$ 1994). Second, they encompass the $\sigma_{0}=25.0 \mathrm{~kg} \mathrm{~m}^{-3}$ isopycnal surface on which the EUC is centered (Tsuchiya et al. 1989) and therefore should provide most of the EUC water. Intermediate waters (IW) are defined as water between $\sigma_{0}=26.7 \mathrm{~kg} \mathrm{~m}^{-3}$ and $\sigma_{0}=27.5 \mathrm{~kg} \mathrm{~m}^{-3}$. They encompass the AAIW, which is characterized by a salt minimum (around 34.5 psu; Fig. 2). Finally, deep waters (DW) are found below $\sigma_{0}=27.5 \mathrm{~kg} \mathrm{~m}^{-3}$.

The contribution of each water mass to the equatorward transport of each one of the three northern straits is reported in Table 2. The outflow transports through the straits mainly occur in the thermocline [TW + lower TW (LTW), from $40 \%$ to $60 \%$ of the total outflow, depending on the strait; Table 2] and intermediate layers (from 25\% to $29 \%$ ). The outflow through the surface layer is comparatively more important for the Vitiaz Strait (14\%) and St. George's Channel (12\%) than for the Solomon Strait $(8 \%)$, whereas the outflow through the deep layer is only important for the deeper Solomon Strait (21\%).

The streamfunctions of Solomon Sea water masses heading to the equator through the three northern straits were calculated as in Blanke et al. (1999) and are shown in Fig. 6 together with the corresponding transports. For each water mass, the pathways followed by particles are similar to those described earlier for the barotropic streamfunction (Fig. 5). However, the relative importance of the main origins of water to the three northern straits depends on density classes (Fig. 6). For the Vitiaz Strait outflow (blue in Fig. 6), waters mostly originate from the south inflow for each water mass. The dominance of the south inflow pathway is stronger within the thermocline, where it provides more than $98 \%$ of the 
TABLE 2. Relative contribution of each water mass to Vitiaz Strait, St. George's Channel, and Solomon Strait total transport (in percentages).

\begin{tabular}{lccc}
\hline \hline Water mass & Vitiaz Strait & $\begin{array}{c}\text { St. George's } \\
\text { Channel }\end{array}$ & Solomon Strait \\
\hline SW & 14 & 12 & 8 \\
TW & 29 & 31 & 20 \\
LTW & 27 & 28 & 21 \\
IW & 29 & 25 & 29 \\
DW & - & 4 & 22 \\
\hline
\end{tabular}

Vitiaz Strait outflowing transport (Fig. 6, percentage shown in the first line of the first column). The south inflow provides $73 \%$ of surface waters and $83 \%$ of intermediate waters, but the Solomon Strait contribution to those water masses (percentages in the second column) is not negligible, accounting for $18 \%$ and $14 \%$, respectively. As for the St. George's Channel contribution to the Vitiaz Strait outflow, it remains weak with only $4 \%$ of SW and $3 \%$ of IW (not shown).

For the St. George's Channel outflow (Fig. 6, green), the dominance of the south inflow pathway is also stronger within the thermocline, where it provides $90 \%$ of the TW and LTW transports. The south inflow is also the main provider of IW (47\%), but it is not the main provider of SW (23\%). The contribution of Solomon Strait

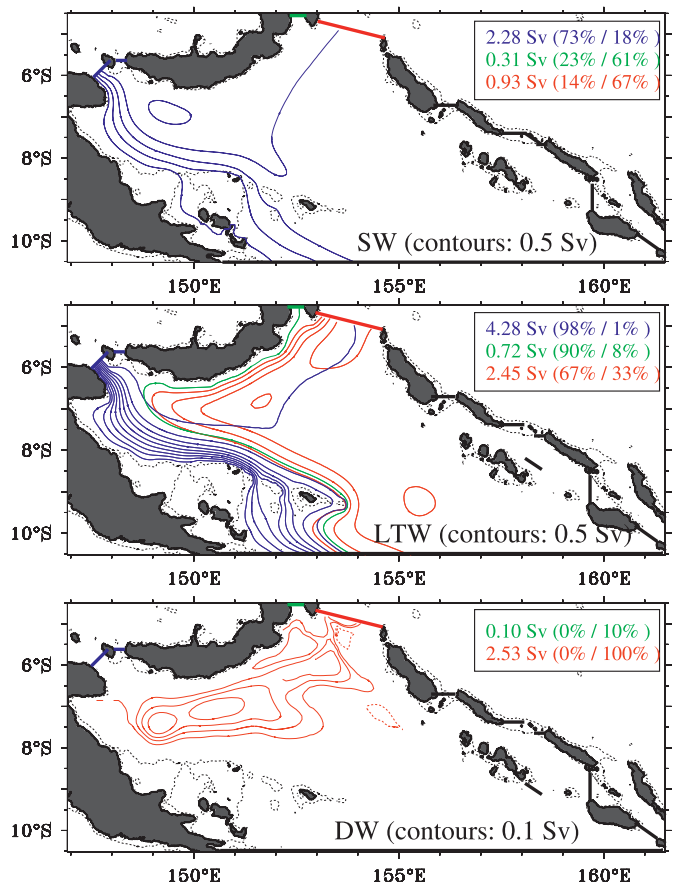

waters to St. George's Channel is nonnegligible for TW, LTW, and DW (between 6\% and 10\%). It is stronger for IW $(37 \%)$ and is even the main source $(61 \%)$ of SW. As for the contribution of the St. George's Channel recirculation, it is almost nil for thermocline waters but is important for DW (90\%), IW (14\%), and SW (13\%) (not shown).

Finally, for the Solomon Strait outflow (Fig. 6, red), recirculations are the main providers of SW (67\%), IW $(57 \%)$, and DW $(100 \%)$, whereas the south inflow pathway is the main provider of thermocline waters $(64 \%$ for TW and $67 \%$ for LTW).

\section{b. Transit times}

The transit time of a particle represents the time required for it to flow from its initial section to its final section. For each route $p$, a statistically representative transit time $t^{p}$ is computed by weighting the transit time of each particle $t_{i}$ by its respective transport $\operatorname{Tr}_{i}$,

$$
t^{p}=\frac{\left(\sum_{i=1}^{n^{p}} t_{i} \times \operatorname{Tr}_{i}\right)}{\left(\sum_{i=1}^{n^{p}} \operatorname{Tr}_{i}\right)},
$$

FIG. 6. Streamfunction averaged for (top left) the surface (SW), (top right) upper thermocline (TW), (middle left) lower thermocline (LTW), (middle right) intermediate (IW), and (bottom) deep (DW) layers in Sv. Contour spacing is $0.5 \mathrm{~Sv}$ except for DW $(0.1 \mathrm{~Sv})$. The total transports through the Vitiaz Strait (blue), St. George's Channel (green), and the Solomon Strait (red) for each layer are mentioned in the box in the top-right corner. The percentages in parentheses represent the part of the transport that is achieved by the south inflow/Solomon Strait pathways. 
TABLE 3. Mean transit times (days) of particles issuing from the south inflow and from the Solomon Strait to join the Vitiaz Strait, St. George's Channel, and the Solomon Strait. Boldface numbers indicate thermocline water.

\begin{tabular}{|c|c|c|c|c|c|c|}
\hline \multicolumn{7}{|c|}{ Mean transit time (days) } \\
\hline & South inflow to & Solomon Strait to & South inflow to & Solomon Strait to & South inflow to & Solomon Strait to \\
\hline & \multicolumn{2}{|c|}{ Vitiaz Strait } & \multicolumn{2}{|c|}{ St. George's Channel } & \multicolumn{2}{|c|}{ Solomon Strait } \\
\hline SW & 53 & 107 & 103 & 42 & 98 & 45 \\
\hline TW & 48 & 227 & 90 & 141 & 111 & 67 \\
\hline LTW & 53 & 195 & 93 & 234 & 120 & 123 \\
\hline IW & 188 & 371 & 206 & 178 & 256 & 149 \\
\hline DW & - & - & 1071 & 447 & 1075 & 107 \\
\hline
\end{tabular}

where $i$ is the particle index and $n^{p}$ is the total number of particles for the considered path.

Particles cross the Solomon Sea very rapidly (Table 3). Indeed, in the surface and thermocline layers, particles coming from the south inflow only take around 1.5 months to reach the Vitiaz Strait, 3 months to reach St. George's Channel, and 3.5 months to reach the Solomon Strait (Table 3). In the thermocline, those quite rapid transit times can be explained by the fact that south inflow waters follow the Solomon Sea WBC system to reach the northern straits, as seen earlier (Fig. 6). This system of currents exhibits high speeds in the thermocline: more than $50 \mathrm{~cm} \mathrm{~s}^{-1}$ on average (AM10) and more than $100 \mathrm{~cm} \mathrm{~s}^{-1}$ in strong flow periods (Lindstrom et al. 1990).

As for the Solomon Strait recirculations, they have a short transit time within the Solomon Sea (Table 3), varying on average from 1.5 (SW) to 5 months (IW). This is because they do not travel long distances (Fig. 6). Solomon Strait waters exiting the Solomon Sea through St. George's Channel and the Vitiaz Strait have to travel longer distances (Fig. 6). As a result, their transit time on average within the thermocline (TW and LTW) is $\sim 7$ months for the Vitiaz Strait and varies from approximately 5 to 8 months for St. George's Channel.

\section{Water mass modifications}

We now examine the modifications to the water masses along the previously described equatorward Solomon Sea routes. The Lagrangian method applied to the Eulerian model outputs enables us to follow the density, temperature, and salinity of particles, which can change along their pathways under the effect of the resolved and parameterized mixing in the model and under the influence of the prescribed atmospheric heat and freshwater fluxes.

\section{a. Density modifications}

We first examine the transport distributions as a function of density for the three outflow routes, at the exits from and entrances into the Solomon Sea. For each strait, the initial transport distributions (for all contributing
Solomon Sea inflows, without distinction) were binned into $0.1 \mathrm{~kg} \mathrm{~m}^{-3}$ density classes. The densities of particles within each specific initial density class [defined in section $4 \mathrm{a}(2)$; Table 1] were followed from their initial section until their final destination. An example is given for MAXW along the Vitiaz Strait routes in Fig. 7, and the complete initial and final histograms are presented in Fig. 8.

The differences between the initial and the final transport distributions as a function of density show the density changes that particles experienced during their crossing of the Solomon Sea. For a specific density class, the more the final distribution has spread in relation to the initial distribution, the more diapycnal mixing there has been. This diapycnal mixing related spreading is illustrated below for MAXW along the Vitiaz Strait routes. The initial transport in the MAXW layer is $0.67 \mathrm{~Sv}$ (Figs. 7, 8a). Particles accounting for this transport have spread over the UTW (36\%), MTW (28\%), and lower SW (LSW; 3\%) density classes during their journey to the Vitiaz Strait (Fig. 7). As a result, only $33 \%$ of those particles remain in the MAXW density class when they reach the Vitiaz Strait. Because the other water masses also experience diapycnal spreading (Fig. 8a), the water found in the MAXW density class at the Vitiaz Strait originates from MTW (38\%), MAXW (33\%), UTW (26\%), and LSW (2\%) (not shown). Diapycnal mixing explains the differences between initial and final transports in density classes, and the MAXW transport at the Vitiaz Strait has decreased slightly, down to $0.65 \mathrm{~Sv}$.

Figure 8 shows that this diapycnal spreading, which qualitatively illustrates diapycnal mixing, is particularly strong for thermocline waters and is more important for the Vitiaz Strait and St. George's Channel routes than for the Solomon Strait routes. Indeed, the St. George's Channel results are very close to those of the Vitiaz Strait.

As for the Solomon Strait routes, the initial transport in the MAXW layer is $0.36 \mathrm{~Sv}$. Because of diapycnal mixing, only $63 \%$ of those particles remain in the MAXW density class when they reach the Solomon Strait, and waters found in the MAXW density class at the Solomon 


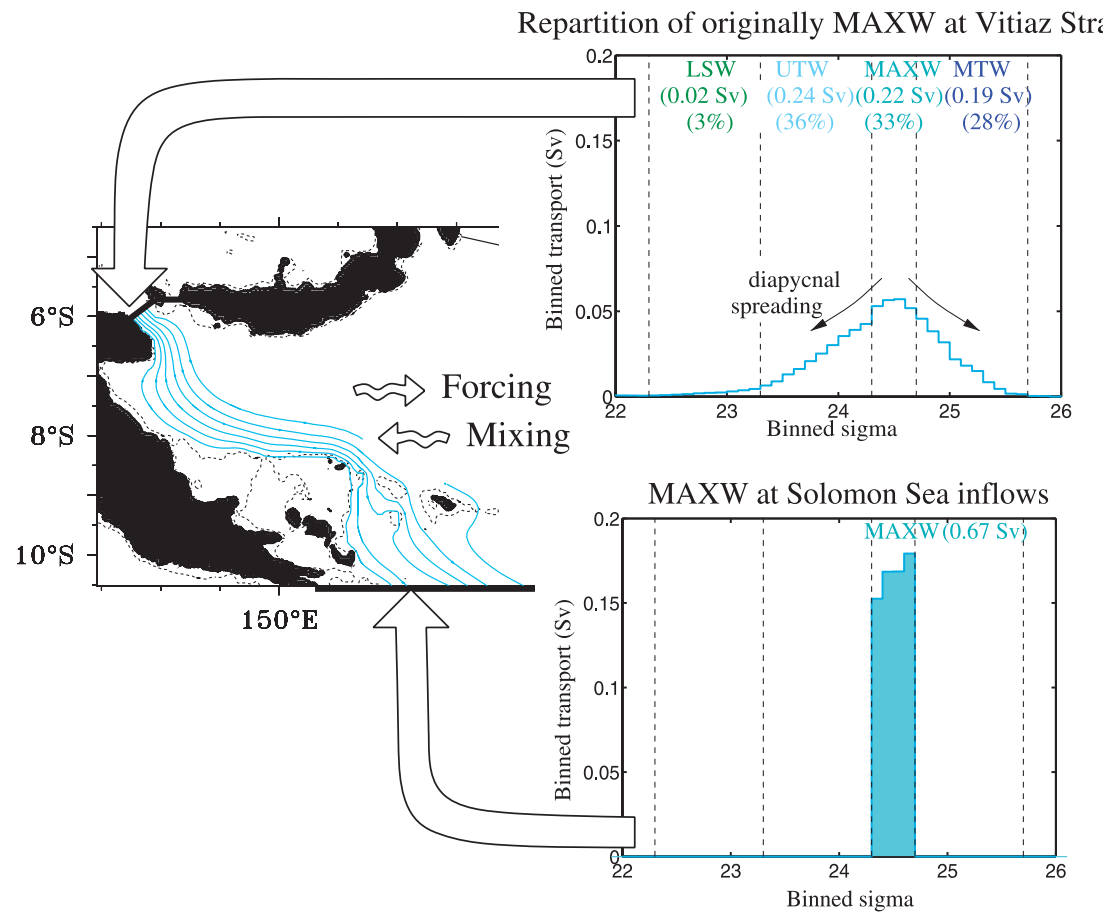

FIG. 7. (bottom) Transport distributions as a function of density for inflowing Solomon Sea MAXW (filled histogram) heading to the Vitiaz Strait. (middle) The pathways followed by those particles are represented. (top) The corresponding distribution of transport at the Vitiaz Strait is represented as a function of density (unfilled histogram).

Strait are originally from MAXW (52\%), MTW (36\%), and UTW (12\%) (not shown). As a result of diapycnal mixing, the final transport in the MAXW layer is $0.42 \mathrm{~Sv}$.

To refine our analysis, we chose to quantify diapycnal mixing on the basis of the variations in particle density along their path. We consider that a particle experiences diapycnal mixing if the change in its density between its initial and final section is greater than $0.1 \mathrm{~kg} \mathrm{~m}^{-3}$. Sensibility tests were conducted on this criterion and produced satisfactory results: the percentages of diapycnal mixing increased significantly if we used a more selective criterion, but their relative proportions among density classes were preserved. The percentages of diapycnal transport for each water mass diagnosed according to this criterion are presented in Table 4 along each of the main Solomon Sea routes that we identified.

This analysis shows that the contribution of diapycnal transport decreases with depth (Table 4). As a result, IW routes are mainly isopycnal, whereas surface routes are mainly diapycnal.

Routes leading to an outflow through the Vitiaz Strait are strongly diapycnal and the proportions of diapycnal transport are roughly comparable for the south inflow ( $81 \%$ for TW) and the Solomon Strait (85\% for TW) pathways (Table 4). As for the St. George's Channel outflow, diapycnal transport is strong $(80 \%$ for $\mathrm{TW})$ for the south inflow route, moderate ( $68 \%$ for TW) for the Solomon Strait route, and weak (26\% for TW; not shown) for the St. George's Channel recirculations (Fig. 5).

Finally, diapycnal transports along the Solomon Strait routes are only dominant for SW and TW originating from the south inflow. Otherwise, isopycnal transports are preponderant (Table 4). Moreover, the relative importance of diapycnal mixing along the different routes is more striking for the Solomon Strait outflow. Indeed, diapycnal mixing for water originating from the south inflow (about $69 \%$ for TW) is roughly twice that for recirculations within the Solomon Strait (about 36\% for TW). Thus, we can distinguish an isopycnal and a diapycnal upper-thermocline (TW) route leading to an outflow through the Solomon Strait.

The analysis therefore confirms that diapycnal mixing is stronger for the Vitiaz Strait routes than for those of St. George's Channel and the Solomon Strait. Moreover, routes originating from the south inflow tend to be more diapycnal than those from the Solomon Strait.

\section{b. Salinity modifications}

We now analyze changes in salinity across the Solomon Sea and the role of diapycnal processes in these changes. We first examine transport distributions as a function of salinity, as we did for density. For each of the three 
Vitiaz Strait routes

a)

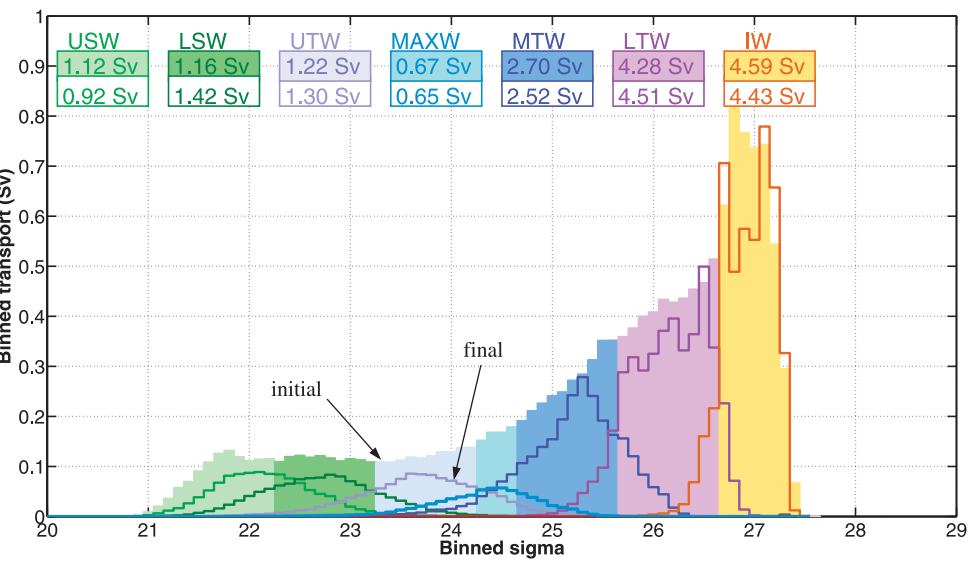

b)

St Georges Channel routes

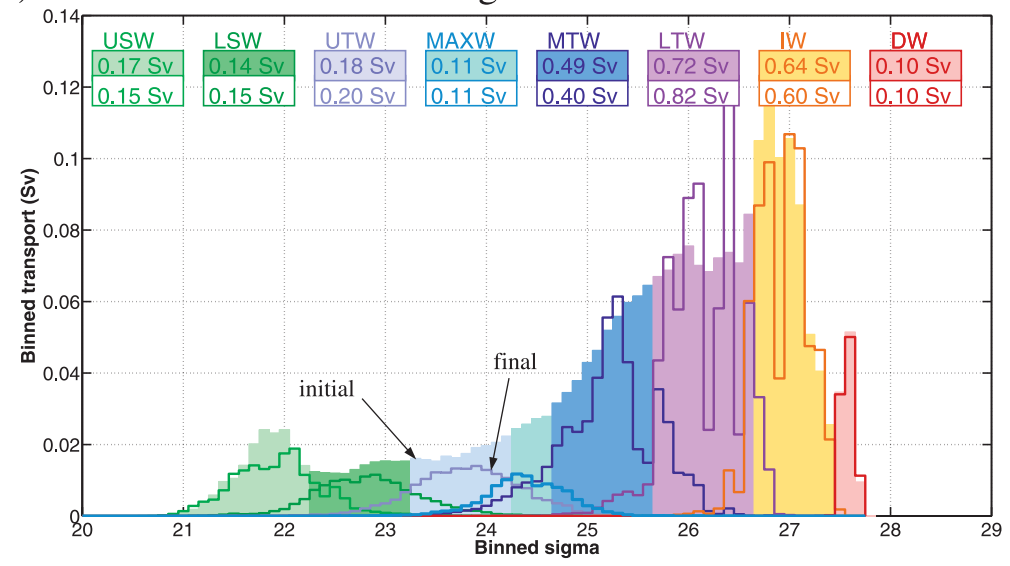

c)

Solomon Strait routes

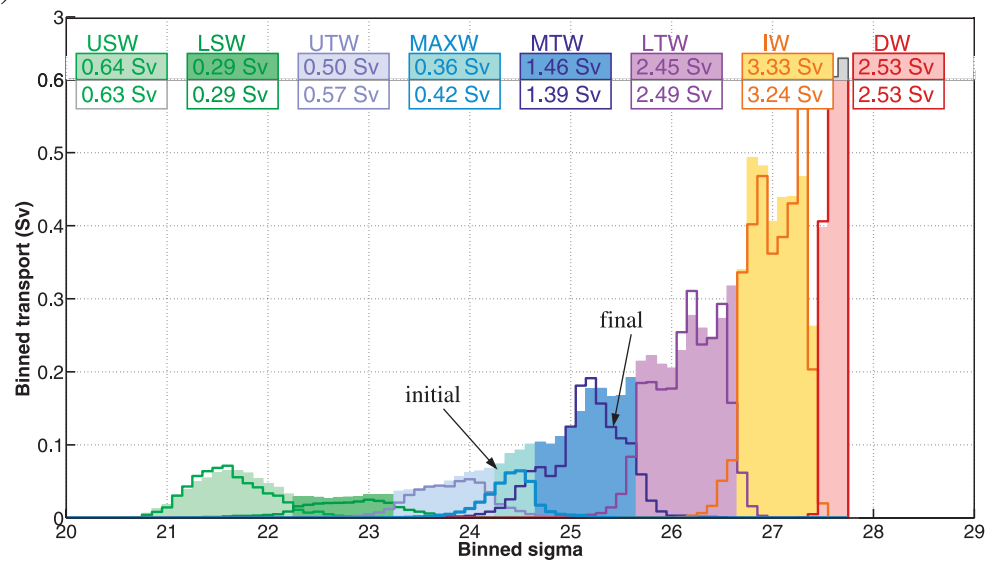

FIG. 8. Transport distributions as a function of density for (a) the Vitiaz Strait, (b) St. George's Channel, and (c) the Solomon Strait routes. The filled histograms correspond to the distribution of transport at the Solomon Sea inflows, whereas the overlain unfilled histograms correspond to the distribution of transport at the exiting strait. Colors refer to the density classes defined in Table 1 . Transports for each water mass are indicated at the top of each panel: the transport in the filled box corresponds to the transport of the water mass at the Solomon Sea inflows, whereas the transport in the white box corresponds to the transport of the water mass at the exiting strait. Note the compressed vertical axis for the Solomon Strait routes. 
TABLE 4. Diapycnal part (\%) of the transport for each pathway. Boldface indicates thermocline water.

\begin{tabular}{|c|c|c|c|c|c|c|}
\hline & South inflow to & Solomon Strait to & South inflow to & Solomon Strait to & South inflow to & Solomon Strait to \\
\hline & \multicolumn{2}{|c|}{ Vitiaz Strait } & \multicolumn{2}{|c|}{ St. George's Channel } & \multicolumn{2}{|c|}{ Solomon Strait } \\
\hline SW & 83 & 93 & 85 & 67 & 84 & 42 \\
\hline TW & 81 & 85 & 80 & 68 & 69 & 36 \\
\hline LTW & 69 & 58 & 62 & 50 & 49 & 26 \\
\hline IW & 39 & 17 & 40 & 9 & 27 & 4 \\
\hline DW & - & - & - & - & 3 & 0 \\
\hline
\end{tabular}

northern strait routes, initial and final transport distributions are binned into 0.02-psu salinity classes (Fig. 9). The comparison of the initial and final transport distributions indicates the changes in salt fluxes along each route. Salt fluxes (Fs) are calculated as follows:

$$
\mathrm{Fs}^{p}=\sum_{i=1}^{n^{p}}\left(S_{i}^{\text {out }}-S_{i}^{\text {in }}\right) \times \operatorname{Tr}_{i},
$$

where $\operatorname{Tr}_{i}$ is the transport of particle $i$ following the considered route $p, S_{i}^{\text {out }}$ is its salinity at the Solomon Sea outflow, and $S_{i}^{\text {in }}$ is its salinity at the Solomon Sea inflow.

The salinity distributions (Fig. 9) exhibit two main peaks characterizing the STMW (high salinities, in excess of $35.5 \mathrm{psu}$, found in the upper part of the thermocline, in blue) and AAIW (low salinities, around 34.5 psu, found in the intermediate layer, in yellow) described in section 3. The salinity distribution encompassed between those two extremes is representative of both SWs (in green) and LTW (in purple). Comparison of the initial and final salinity distributions shows that TW become fresher (negative salt flux) whereas LTW and IW become saltier (positive salt flux) during their journey through the Solomon Sea. This results in a reduction of the vertical salinity gradient: the STMW salinity maximum is eroded, and the corresponding salt flux is transferred downward to AAIW. Salt fluxes are more intense for TW (up to $-52210^{-3} \mathrm{psu}$ Sv for the Vitiaz Strait routes; Fig. 9a) than for LTW and IW. They are null for DW, because changes in salinity are very limited for this water mass. As for SW, salt fluxes are also weak when we consider the cumulative contribution of all the inflows to a given strait route. Finally, these salinity changes across the Solomon Sea are more important (stronger salt fluxes; Fig. 9) for the Vitiaz Strait routes than for those of St. George's Channel and the Solomon Strait.

For each strait, salt fluxes are mostly due to the contribution of the south inflow routes. This is shown by comparing the salt fluxes computed for all contributing Solomon Sea inflows, considered without distinction (Fig. 9), with the salt fluxes computed for the south inflow contribution alone (Table 5, first column). For instance, the south inflow route is responsible for $-77 \times 10^{-3} \mathrm{psu} \mathrm{Sv}$ (Table 5) out of $-80 \times 10^{-3}$ psu Sv (Fig. 9) for the TW salt flux associated with the St. George's Channel outflow. Salt fluxes associated with the Solomon Strait inflow routes are thus negligible in general, except for Solomon Strait recirculations where they significantly reinforce the salt fluxes associated with the south inflow route. Moreover, spiciness anomalies (density-compensating temperature and salinity anomalies) carried by the South Pacific STC mainly enter the Solomon Sea from its southern entrance because of the distribution of currents (AM10). The south inflow routes to the equatorial Pacific are thus the most relevant routes from a climatic point of view, and we will therefore focus on these routes in the following sections.

We now examine the importance of diapycnal processes in the salinity modifications observed. A breakdown of the salt fluxes associated with the south inflow routes to the equator into a diapycnal component (computed from the particles experiencing diapycnal transport as defined in section 5a) and an isopycnal component (computed from the particles that remain at the same density) shows that diapycnal mixing is responsible for most of the salt fluxes (see percentages in Table 5). Indeed, the proportion of salt fluxes explained by diapycnal mixing reaches $\approx 88 \%$ for the TW, LTW, and IW along the south inflow to the Vitiaz Strait route $(\approx 80 \%$ for St. George's Channel route and $\approx 70 \%$ for the Solomon Strait route), and it is even stronger for SW (Table 5). This diapycnal mixing implies that thermocline layers (TW) export high salinities toward/receive low salinities from the surrounding density classes, which leads to a negative salt flux for TW and positive salt fluxes for LTW, IW, and SW, as seen earlier (Table 5). As precipitation dominates evaporation over the Solomon Sea (e.g., Béranger et al. 1999), a strong negative salt flux (freshening) is imposed from the atmospheric forcing to ocean surface layers (SW). It seems likely that the strong positive SW salt flux associated with diapycnal mixing dominates the negative SW salt flux associated with atmospheric forcing.

Let us now consider the efficiency of diapycnal and isopycnal mixing on the modifications to salinity. Along the south inflow to the Vitiaz Strait route, the TW salinity modification (salt trend in Table 5) associated with diapycnal mixing reaches $-0.14 \mathrm{psu}$, whereas the one associated with isopycnal mixing is only -0.08 psu (Table 5). 
a)

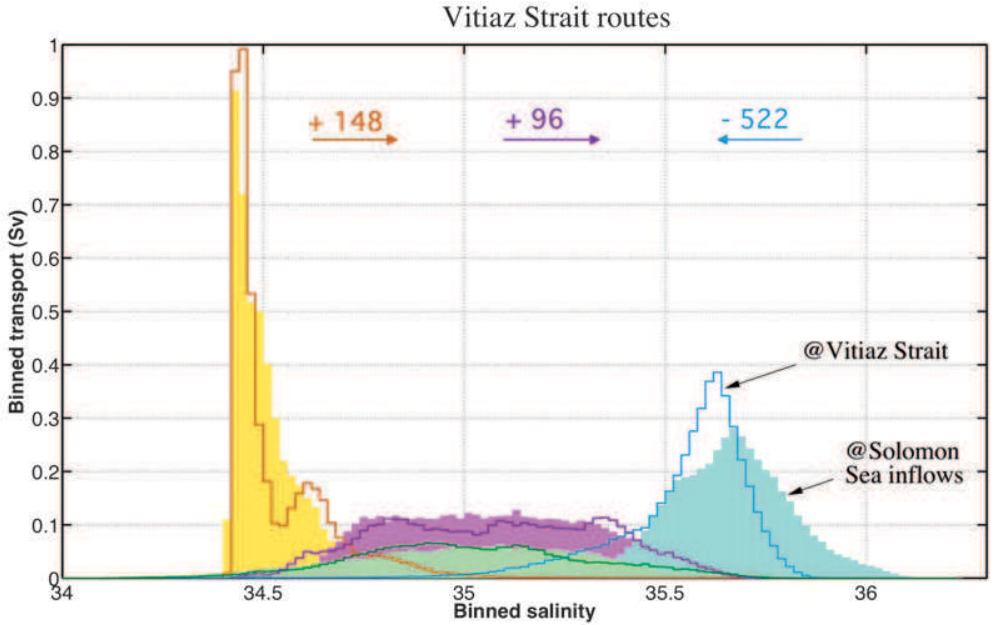

b)

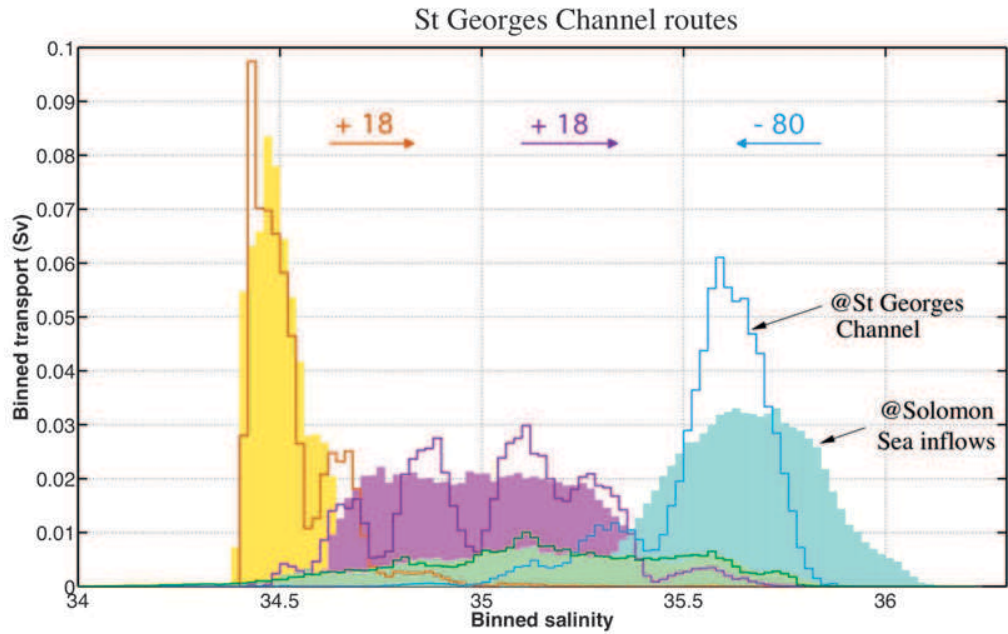

c)

Solomon Strait routes

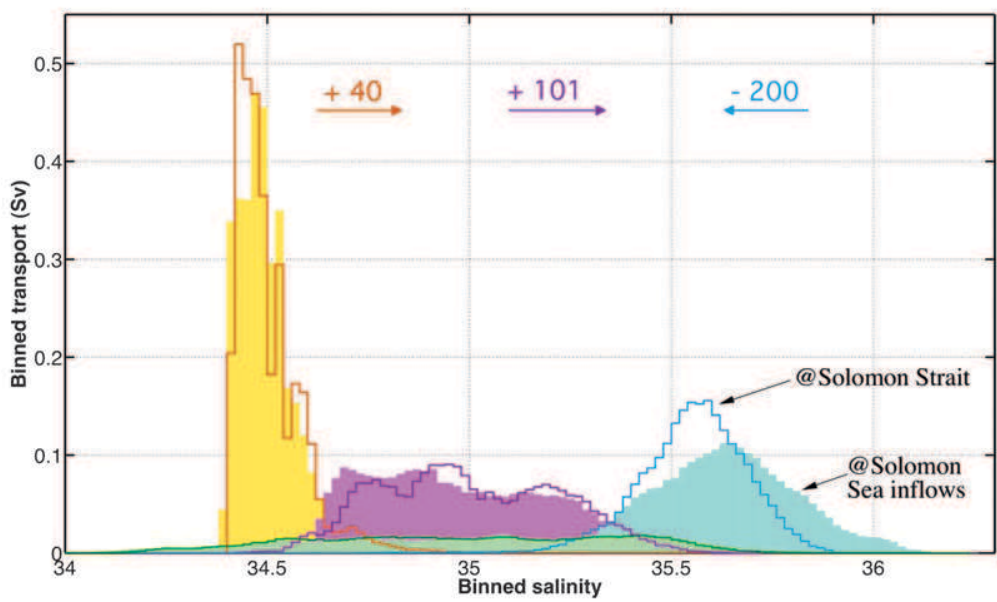

FIG. 9. Transport distributions as a function of salinity for the (a) Vitiaz Strait, (b) St. George's Channel, and (c) Solomon Strait routes. The filled histograms correspond to the distribution of transport at the Solomon Sea inflows, whereas the overlain unfilled histograms correspond to the distribution of transport at the exiting strait. Colors refer to water mass density classes defined in Table 1. UTW, MAXW, and MTW have been grouped into TW and are plotted in blue. For clarity reasons and because the associated salt fluxes are almost null, we chose not to plot the DW. The mean salinity of those waters is about $34.6 \mathrm{psu}$ for all pathways. Salt fluxes $\left(10^{-3} \mathrm{psu} \mathrm{Sv}\right)$ from the Solomon Sea inflows to the exiting strait are specified for TW, LTW, and IW above the arrows. 
TABLE 5. Salt fluxes $\left(10^{-3} \mathrm{psu} \mathrm{Sv}\right)$ and associated salinity trend (salt flux divided by the corresponding transport, psu, in italics) per water mass associated with the south inflow to the (top) Vitiaz Strait, (middle) St. George's Channel, and (bottom) Solomon Strait pathways. The values in parentheses are the percentages given in the diapycnal salt flux column that represent the part of the total salt flux (in boldface) explained by diapycnal mixing.

\begin{tabular}{|c|c|c|c|c|c|}
\hline \multicolumn{6}{|c|}{ South inflow to Vitiaz Strait } \\
\hline & \multirow{2}{*}{$\begin{array}{c}\text { Tot } \\
\text { Salt flux }\end{array}$} & \multicolumn{2}{|c|}{ Diapycnal } & \multicolumn{2}{|c|}{ Isopycnal } \\
\hline & & Salt flux & Salt trend & Salt flux & Salt trend \\
\hline SW & +6 & +11 (183) & +0.01 & -5 & -0.02 \\
\hline TW & -536 & $-476(89)$ & -0.14 & -60 & -0.08 \\
\hline LTW & +85 & $+74(87)$ & +0.03 & +11 & +0.01 \\
\hline IW & +162 & $+142(88)$ & +0.10 & +20 & +0.01 \\
\hline \multicolumn{6}{|c|}{ South inflow to St. George's Channel } \\
\hline & \multirow{2}{*}{$\begin{array}{c}\text { Tot } \\
\text { Salt flux }\end{array}$} & \multicolumn{2}{|c|}{ Diapycnal } & \multicolumn{2}{|c|}{ Isopycnal } \\
\hline & & Salt flux & Salt trend & Salt flux & Salt trend \\
\hline SW & +7 & $+6(86)$ & +0.11 & +1 & +0.06 \\
\hline TW & -77 & $-65(84)$ & -0.13 & -12 & -0.09 \\
\hline LTW & +14 & $+11(79)$ & +0.03 & +3 & +0.01 \\
\hline IW & +16 & $+13(81)$ & +0.11 & +3 & +0.02 \\
\hline \multicolumn{6}{|c|}{ South inflow to Solomon Strait } \\
\hline & \multirow{2}{*}{$\begin{array}{c}\text { Tot } \\
\text { Salt flux }\end{array}$} & \multicolumn{2}{|c|}{ Diapycnal } & \multicolumn{2}{|c|}{ Isopycnal } \\
\hline & & Salt flux & Salt trend & Salt flux & Salt trend \\
\hline SW & +5 & $+5(100)$ & +0.04 & 0 & +0.01 \\
\hline TW & -158 & $-112(71)$ & -0.13 & -46 & -0.11 \\
\hline LTW & +60 & $+35(58)$ & +0.04 & +25 & +0.03 \\
\hline IW & +40 & $+28(70)$ & +0.08 & +12 & +0.01 \\
\hline
\end{tabular}

Diapycnal mixing is also more efficient than isopycnal mixing in terms of salinity changes in the TW along the south inflow to the St. George's Channel and Solomon Strait routes (Table 5). The efficiency of diapycnal mixing is even greater for SW, LTW, and especially IW. On one hand, along the south inflow to the Vitiaz Strait route, SW become saltier through strong diapycnal mixing $(+0.01 \mathrm{psu})$, but the associated salt flux is partly compensated by weaker isopycnal mixing, which tends to freshen SW ( $-0.02 \mathrm{psu})$. On the other hand, diapycnal mixing induces salinity trends that are substantially higher for LTW-and more than 6 times higher for IW-than those induced by isopycnal mixing for the south inflow routes (Table 5).

All in all, the salinity of waters advected by the lower branch of the STC from the subtropics to the EUC is significantly modified during transit through the Solomon Sea. This is mainly due to diapycnal mixing, which is revealed to be more efficient than isopycnal mixing.

\section{c. Temperature modifications}

Water mass modifications in the Solomon Sea are finally analyzed by diagnosing the temperature modifications
TABLE 6. As in Table 5, but for heat fluxes $\left(10^{-2} \mathrm{TW}\right)$ and their associated temperature trends $\left({ }^{\circ} \mathrm{C}\right)$.

\begin{tabular}{|c|c|c|c|c|c|}
\hline \multicolumn{6}{|c|}{ South inflow to Vitiaz Strait } \\
\hline & \multirow{2}{*}{$\begin{array}{c}\text { Tot } \\
\text { Heat flux }\end{array}$} & \multicolumn{2}{|c|}{ Diapycnal } & \multicolumn{2}{|c|}{ Isopycnal } \\
\hline & & Heat flux & Trend & Heat flux & Trend \\
\hline SW & -144 & $-139(91)$ & -0.25 & -5 & -0.04 \\
\hline TW & -377 & $-308(82)$ & -0.12 & -68 & -0.22 \\
\hline LTW & +284 & $+272(96)$ & +0.23 & +12 & +0.02 \\
\hline IW & +695 & $+622(89)$ & +1.04 & +73 & +0.08 \\
\hline \multicolumn{6}{|c|}{ South inflow to St. George's Channel } \\
\hline & \multirow{2}{*}{$\begin{array}{c}\text { Tot } \\
\text { Heat flux }\end{array}$} & \multicolumn{2}{|c|}{ Diapycnal } & \multicolumn{2}{|c|}{ Isopycnal } \\
\hline & & Heat flux & Trend & Heat flux & Trend \\
\hline SW & -8 & $-8(100)$ & -0.34 & +0 & +0.12 \\
\hline TW & -90 & $-78(87)$ & -0.33 & -12 & -0.23 \\
\hline LTW & +39 & $+33(85)$ & +0.20 & +6 & +0.06 \\
\hline IW & +73 & $+60(82)$ & +1.22 & +13 & +0.18 \\
\hline \multicolumn{6}{|c|}{ South inflow to Solomon Strait } \\
\hline & \multirow{2}{*}{$\begin{array}{c}\text { Tot } \\
\text { Heat flux }\end{array}$} & \multicolumn{2}{|c|}{ Diapycnal } & \multicolumn{2}{|c|}{ Isopycnal } \\
\hline & & Heat flux & Trend & Heat flux & Trend \\
\hline SW & $-\mathbf{3}$ & $-3(100)$ & -0.07 & 0 & +0.03 \\
\hline TW & -69 & $-22(32)$ & -0.10 & -46 & -0.27 \\
\hline LTW & +155 & $+101(65)$ & +0.31 & +54 & +0.16 \\
\hline IW & $+\mathbf{1 7 0}$ & $+125(74)$ & +0.90 & +45 & +0.12 \\
\hline
\end{tabular}

and the importance of diapycnal processes in explaining them.

Because density changes are mainly driven by temperature changes, the histograms of transport as a function of temperature resemble the histograms of transport as a function of density (Fig. 8) and are not shown. As with the salinity modifications, we will only consider the temperature modifications associated with the south inflow routes. In this regard, heat fluxes $(\mathrm{Fq})$ are calculated as

$$
\mathrm{Fq}^{p}=\sum_{i=1}^{n^{p}} \rho_{0} C_{p}\left(T_{i}^{\text {out }}-T_{i}^{\mathrm{in}}\right) \times \operatorname{Tr}_{i},
$$

where $\operatorname{Tr}_{i}$ is the transport of particle $i$ following the considered route $p, T_{i}^{\text {out }}$ is its temperature at the Solomon Sea outflow, $T_{i}^{\text {in }}$ is its temperature at the south Solomon Sea inflow, $\rho_{0}$ is a mean density $\left(1020 \mathrm{~kg} \mathrm{~m}^{-3}\right)$, and $C_{p}$ is the heat capacity of water under constant pressure. Heat fluxes are listed in Table 6.

Along the south inflow routes, SW and TW are cooled (negative heat fluxes, first column of Table 6), whereas LTW and IW are warmed (positive heat fluxes). Thus, heat is transferred downward, and the vertical temperature gradient is reduced during the crossing of the Solomon Sea. Heat fluxes, like salt fluxes, for south inflow waters exiting the Solomon Sea through the Vitiaz Strait are stronger than those through St. George's Channel or the Solomon 
Strait (Table 6). The breakdown of the heat flux into its diapycnal and isopycnal components (same methodology as for salt fluxes) shows that diapycnal mixing is responsible for most of the heat fluxes along the south inflow pathways (see percentages in Table 6). This is especially true for the south inflow to the Vitiaz Strait and St. George's Channel routes, where diapycnal mixing explains more than $80 \%$ of the heat fluxes for each water mass. Diapycnal mixing plays a weaker role in explaining heat fluxes associated with the south inflow to the Solomon Strait route, and it is even less important (32\%) than isopycnal mixing in the upper thermocline layer (TW). As observed for salinity changes, temperature changes due to diapycnal mixing are globally greater than those due to isopycnal mixing, especially for IW, where temperature variations due to diapycnal mixing can reach about $1^{\circ} \mathrm{C}$ (Table 6). As for TW, diapycnal mixing is more efficient than isopycnal mixing in terms of temperature variations only along the south inflow to the St. George's Channel route (Table 6).

All in all, diapycnal mixing is more efficient than isopycnal mixing, and it explains the major part of the observed heat fluxes for all the water masses along the south inflow routes to the three northern straits (except for the TW along the south inflow to the Vitiaz and Solomon Strait routes).

\section{Conclusions and discussion}

Because the western boundary currents (WBCs) of the Solomon Sea are the main source of the Equatorial Undercurrent (EUC; Tsuchiya et al.1989), changes to the water mass occurring in this region could impact on the equatorial mass field with potential consequences for the equatorial climate and for the low-frequency modulation of El Niño-Southern Oscillation (ENSO; e.g., Gu and Philander 1997; Luo et al. 2005).

Because available in situ data are scarce in this remote region, modeling is required to diagnose Solomon Sea equatorward pathways and the modifications to their associated water masses. A high-resolution $\left(1 / 12^{\circ}\right)$ model of the Solomon Sea (already validated for the circulation in AM10) was implemented to resolve the complex circulation and eddy field structure. The model includes a parameterization of the vertical mixing induced by the dissipation of internal tides. The good agreement between our simulation and observations both in terms of water mass properties and circulation allows us to analyze the water mass pathways and modifications in the Solomon Sea from our model with some confidence in the robustness of our results. A Lagrangian analysis (Blanke and Raynaud 1997) enabled us to separate the total 3D Eulerian circulation into different pathways according to their origins and density, as has already been done in the Indonesian region (Koch-Larrouy et al. 2008). The main part of the Solomon Sea equatorward flow circulates through the Vitiaz and Solomon straits, in the thermocline and intermediate layers, and involves water originating from the Solomon Sea south inflow, especially for the thermocline layer, and from the Solomon Strait.

Water masses originating from the Solomon Strait recirculate in the Solomon Sea: they head toward the NGCU to escape through the Vitiaz Strait, or they make a U-turn to join the NBCU and escape through St. George's Channel or return to the Solomon Strait. Water masses originating from the south inflow are advected by the strong NGCU toward the Vitiaz Strait and then by the NBCU to St. George's Channel and the Solomon Strait. The strength of these WBCs explains the relatively short transit time for waters crossing the Solomon Sea along these routes.

The Lagrangian calculations enabled us to compare the properties of particles along their trajectories from their entrance into the Solomon Sea to their exit. Changes in density were depicted for each diagnosed route. Along the south inflow routes to the three northern Solomon Sea straits, diapycnal mixing is preponderant and more efficient in terms of water mass modification than isopycnal mixing. By contrast, the Solomon Strait recirculations are peculiar because they are mostly isopycnal.

Salinity and temperature changes were also diagnosed. Diapycnal mixing is responsible for a reduction of the vertical $T-S$ gradients over the water column along the south inflow routes and explains the major part of the modeled heat and salt changes. Water from the upper part of the thermocline, which may eventually feed the EUC and is characterized by a salt maximum, is freshened by freshwater input from the surface, the lower part of the thermocline and the intermediate layers. In the thermocline (TW), transport-weighted salt changes along south inflow pathways are -0.11 psu. As for the temperature, strong diapycnal mixing results in a downward export of heat from the surface to deeper layers. Mean temperature changes in the upper part of the thermocline (TW) along the south inflow routes are $-0.13^{\circ} \mathrm{C}$ to the Vitiaz Strait, $-0.31^{\circ} \mathrm{C}$ to St. George's Channel, and $-0.16^{\circ} \mathrm{C}$ to the Solomon Strait.

The impact of the tidal mixing parameterization used in this study was assessed by comparing our reference simulation with another simulation performed without tidal mixing parameterization. Tidal mixing reinforces diapycnal mixing (Fig. 3), results in an improvement in the modeled water mass structure within the Solomon Sea (Fig. 4) and increases both the downward heat transfer and the salt export from the thermocline saltier waters to the surface, low thermocline, and intermediate layers (Fig. 10). 


\section{SALT FLUXES}

All Solomon Sea inflows to Vitiaz Strait

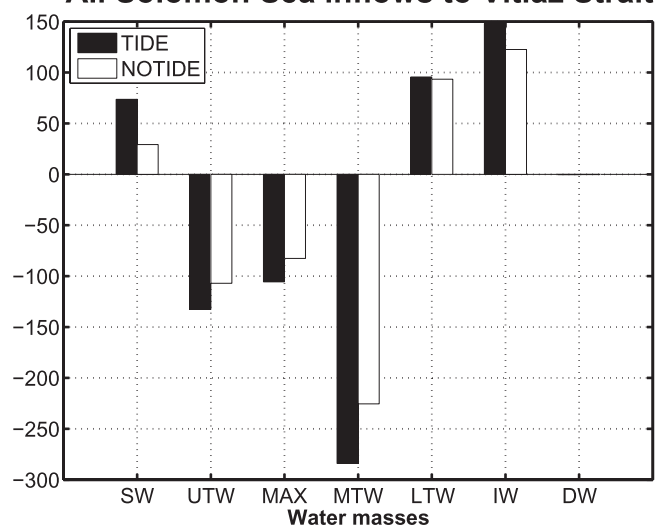

All Solomon Sea inflows to StGeorges Strait

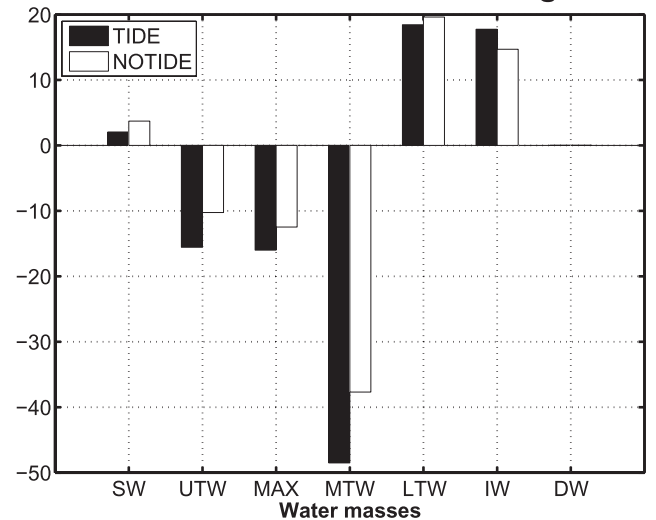

All Solomon Sea inflows to Solomon Strait

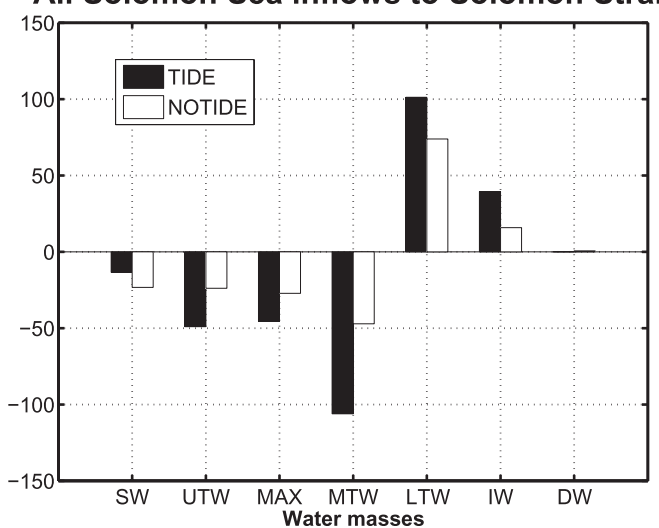

HEAT FLUXES

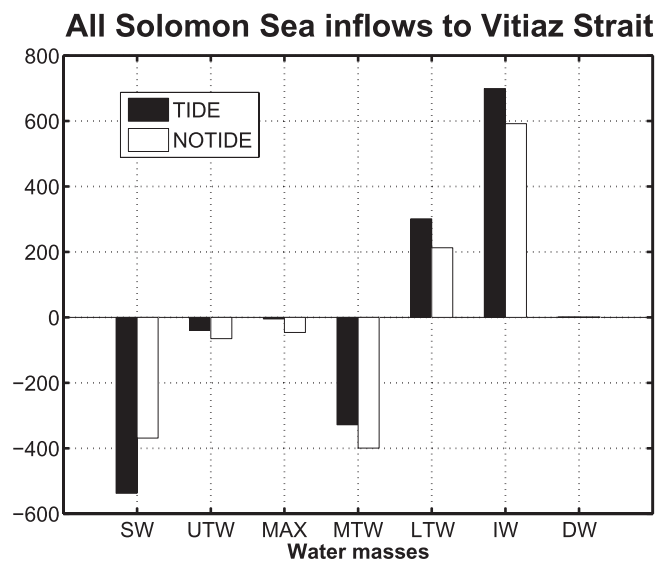

All Solomon Sea inflows to StGeorges Strait

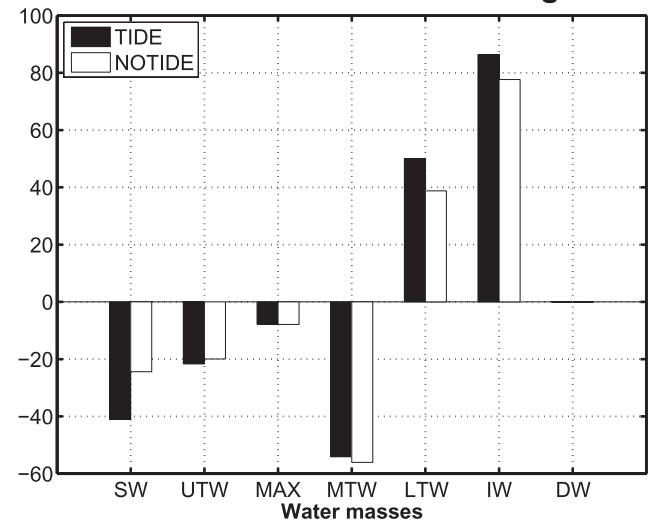

All Solomon Sea inflows to Solomon Strait

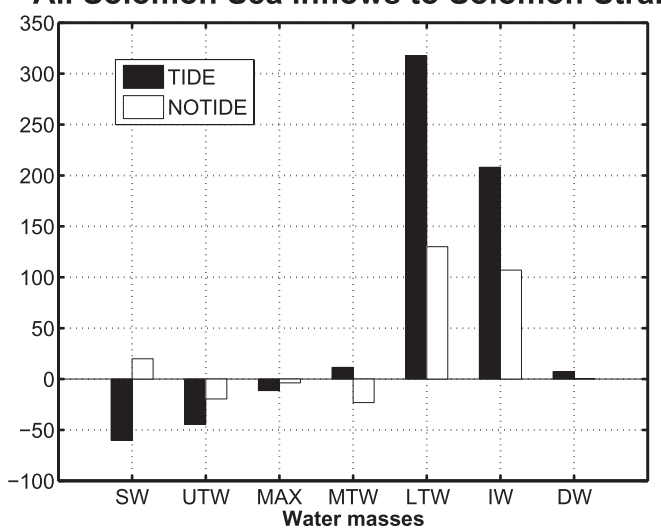

FIG. 10. (left) Salt fluxes $\left(10^{-3} \mathrm{psu} \mathrm{Sv}\right)$ and (right) heat fluxes $\left(10^{-2} \mathrm{TW}\right)$ per water masses for the (top) Vitiaz Strait, (middle) St. George's Channel, and (bottom) Solomon Strait routes for the TIDE (black bars) and NOTIDE (white bars) experiments. Note the different axis scale for each plot. Fluxes associated with DW are almost null.

Future studies could further explore modifications to water masses in the Solomon Sea with the help of additional data, such as that currently being collected or planned as part of the CLIVAR/SPICE program. This would help reduce current uncertainties relating to available data and enable a more complete assessment of our modeling results.
Improvements in the understanding of the physical processes that may affect the properties of water masses and the development of parameterizations to take such processes into account in models should considerably enhance further analysis of the changes observed in Solomon Sea water masses. With regard to tidal mixing, Fig. 2 shows that the formulation we used for the Solomon Sea 


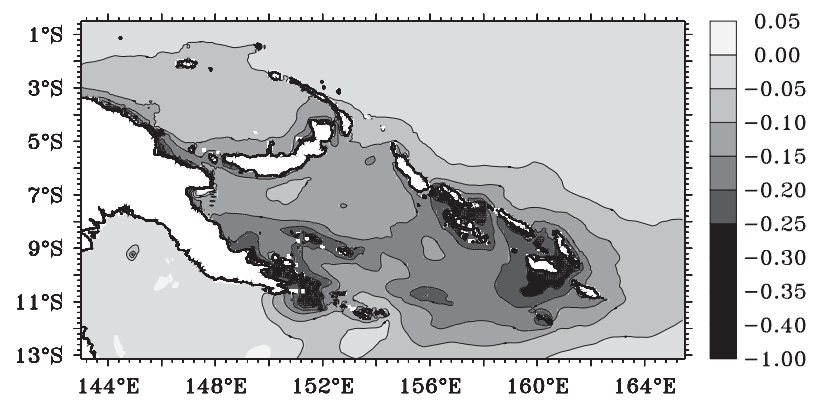

FIG. 11. The TIDE mean SST minus NOTIDE mean SST $\left({ }^{\circ} \mathrm{C}\right)$.

might overestimate erosion of the STMW salinity maximum, whereas erosion of the AAIW salinity minimum might be underestimated. Outside the Solomon Sea, only $1 / 3$ of tidal energy was taken into account and is dissipated at the ocean bottom, where internal tides are generated. However, barotropic to baroclinic tidal energy transfers are important both upstream and downstream of the Solomon Sea, respectively, in the Coral Sea and offshore from New Ireland (Fig. 3). Further analyses are needed to develop an adapted tidal mixing parameterization outside the Solomon Sea, in the open ocean, to take account of the remaining $2 / 3$ of the energy propagated/dissipated and of the potential associated changes to water masses. This might reduce the differences between the observed and modeled thermocline water properties in the Coral Sea. Finally, physical processes related to the strong NICU and NGCU along the northern coast of PNG may imply additional diapycnal mixing and water mass modifications in subtropical water transiting through the Solomon Sea to reach the equator.

It is of prime importance to study the low-frequency variability of Solomon Sea water mass modifications and their potential impact on the equatorial Pacific conditions and climate. This involves assessing whether the subtropical spiciness anomalies carried by the South $\mathrm{Pa}$ cific STC to the equator are damped within the Solomon Sea, which would reduce their impact on the equatorial Pacific climate. Furthermore, the increase in downward heat transfer related to tidal mixing is responsible for a decrease in SST over the Solomon Sea (Fig. 11). The averaged SST drop from the NOTIDE to TIDE experiments is $-0.2^{\circ} \mathrm{C}$ over the region where the Koch-Larrouy et al. (2007) tidal parameterization was applied (Fig. 3). Assessing the impact of such changes on atmospheric convection and more generally on tropical mean state climate in a coupled model would be interesting. Indeed, a recent paper has shown that the tidal induced vertical mixing in the Indonesian region is able to modify local atmospheric convection and tropical ocean/atmosphere variability such as ENSO and the Indian Ocean dipole (Koch-Larrouy et al. 2010).
Acknowledgments. The authors thank S. Cravatte, W. S. Kessler, and the two anonymous reviewers for their helpful comments on this manuscript. This work is part of the CLIVAR/SPICE international program and was supported by the Centre National d'Etude Spatiales (CNES), the Centre National de Recherche Scientifique (CNRS), and the Institut de Recherche pour le Développement (IRD). Calculations were performed using HPC resources from GENCI-IDRIS (Grant 2009-011279). The authors also acknowledge the use of the ARIANE Lagrangian tool (http://stockage.univ-brest.fr/ grima/ Ariane) and thank B. Blanke and N. Grima for their help in taking ARIANE in hands. Hydrographic data were extracted from the Coriolis database (http://www. coriolis.eu.org). The authors would also like to thank F. Lyard for providing them with the barotropic to baroclinic tidal energy transfer data over the region of the study.

\section{REFERENCES}

Arbic, B., S. Garner, R. Hallberg, and H. Simmons, 2004: The accuracy of surface elevations in forward global barotropic and baroclinic tide models. Deep-Sea Res. II, 51 (25-26), 3069-3101.

Béranger, K., L. Siefridt, B. Barnier, E. Garnier, and H. Roquet, 1999: Evaluation of operational ECMWF surface freshwater fluxes over oceans during 1991-1997. J. Mar. Syst., 22, 13-36.

Bessières, L., G. Madec, and F. Lyard, 2008: Global tidal residual mean circulation: Does it affect a climate OGCM? Geophys. Res. Lett., 35, L03609, doi:10.1029/2007GL032644.

Blanke, B., and P. Delecluse, 1993: Variability of the tropical Atlantic Ocean simulated by a general circulation model with two different mixed-layer physics. J. Phys. Oceanogr., 23, 1363-1388.

-, and S. Raynaud, 1997: Kinematics of the Pacific Equatorial Undercurrent: An Eulerian and Lagrangian approach from GCM results. J. Phys. Oceanogr., 27, 1038-1053.

_ - M. Arhan, G. Madec, and S. Roche, 1999: Warm water paths in the equatorial Atlantic as diagnosed with a general circulation model. J. Phys. Oceanogr., 29, 2753-2768.

Cravatte, S., A. Ganachaud, Q.-P. Duong, W. S. Kessler, G. Eldin, and P. Dutrieux, 2011: Observed circulation in the Solomon Sea from SADCP data. Prog. Oceanogr., 88, 116-130.

Egbert, G., and R. Ray, 2000: Significant tidal dissipation in the deep ocean inferred from satellite altimeter data. Nature, 405, $775-778$.

Fine, R. A., R. Lukas, F. Bingham, M. Warnar, and R. Gammon, 1994: The western equatorial Pacific: A water mass crossroads. J. Geophys. Res., 99, $25063-25080$.

Fukumori, I., T. Lee, B. Cheng, and D. Menemenlis, 2004: The origin, pathway, and destination of Niño-3 water estimated by a simulated passive tracer and its adjoint. J. Phys. Oceanogr., 34, 582-604.

Ganachaud, A., and Coauthors, 2007: Southwest Pacific Ocean Circulation and Climate Experiment (SPICE)—Part I: Scientific background. CLIVAR/NOAA Tech. Rep., 44 pp.

Gordon, C., and R. Corry, 1991: A model simulation of the seasonal cycle in the tropical Pacific Ocean using climatological and modeled surface forcing. J. Geophys. Res., 96, 847-864.

Gu, D., and S. G. H. Philander, 1997: Interdecadal climate fluctuations that depend on exchanges between the tropics and the extratropics. Science, 275, 805-807. 
Holbrook, N. J., and A. M. Maharaj, 2008: Southwest Pacific subtropical mode water: A climatology. Prog. Oceanogr., 77, 298-315.

Jayne, S. R., and L. C. St. Laurent, 2001: Parameterizing tidal dissipation over rough topography. Geophys. Res. Lett., 28, 811-814.

Kleeman, R., J. P. McCreary, and B. A. Klinger, 1999: A mechanism for the decadal variation of ENSO. Geophys. Res. Lett., 26, 743-747.

Koch-Larrouy, A., G. Madec, P. Bourruet-Aubertot, T. Gerkema, L. Bessières, and R. Molcard, 2007: On the transformation of Pacific Water into Indonesian Throughflow Water by internal tidal mixing. Geophys. Res. Lett., 34, L04604, doi:10.1029/ 2006GL028405.

, — - B. Blanke, and R. Molcard, 2008: Water mass transformation along the Indonesian Throughflow in an OGCM. Ocean Dyn., 58 (3-4), 289-309.

- M. Mengaigne, P. Terray, G. Madec, and S. Masson, 2010: Tidal mixing in the Indonesian Seas and its effect on the tropical climate system. Climate Dyn., 34, 891-904.

Large, W., and S. Yeager, 2009: The global climatology of an interannually varying air-sea flux data set. Climate Dyn., 33, 341-364.

Levitus, S., and Coauthors, 1998: Introduction. Vol. 1, World Ocean Database 1998, NOAA Atlas NESDIS 18, 346 pp.

Lindstrom, E., J. Butt, R. Lukas, and S. Godfrey, 1990: The flow through Vitiaz Strait and St. George's Channel, Papua New Guinea. The Physical Oceanography of Sea Strait, Kluwer Academic, 171-189.

Luo, Y., L. Rothstein, R. Zhang, and A. Busalacchi, 2005: On the connection between South Pacific subtropical spiciness anomalies and decadal equatorial variability in an ocean general circulation model. J. Geophys. Res., 110, C10002, doi:10.1029/ 2004JC002655.

Madec, G., 2008: NEMO ocean engine. Institut Pierre Simon Laplace (IPSL), France Tech. Rep. 27, 300 pp.
McCreary, J., and P. Lu, 1994: On the interaction between the subtropical and the equatorial oceans: The subtropical cell. J. Phys. Oceanogr., 24, 466-497.

Melet, A., L. Gourdeau, W. Kessler, J. Verron, and J. Molines, 2010a: Thermocline circulation in the Solomon Sea: A modeling study. J. Phys. Oceanogr., 40, 1302-1319.

$\longrightarrow,-$, and J. Verron, 2010b: Variability of the Solomon Sea circulation from altimetry sea level data. Ocean Dyn., 60, 883900, doi:10.1007/s10236-010-0302-6.

Niwa, Y., and T. Hibiya, 2001: Numerical study of the spatial distribution of the $\mathrm{M}_{2}$ internal tide in the Pacific Ocean. J. Geophys. Res., 106 (C10), 22 441-22 449.

Qu, T., and E. J. Lindstrom, 2002: A climatological interpretation of the circulation in the western South Pacific. J. Phys. Oceanogr., 32, 2492-2507.

Ridgway, K. R., J. R. Dunn, and J. L. Wilkin, 2002: Ocean interpolation by weighted least squares: Application to the waters around Australia. J. Atmos. Oceanic Technol., 19, 1357-1375.

Schneider, N., 2004: The response of the tropical climate to the equatorial emergence of spiciness anomalies. J. Climate, 17, 1083-1095.

Simmons, H., R. Hallberg, and B. Arbic, 2004: Internal wave generation in a global baroclinic tide model. Deep-Sea Res. II, 51, 3043-3068.

Sokolov, S., and S. Rintoul, 2000: Circulation and water masses of the southwest Pacific: WOCE section 11, Papua New Guinea to Tasmania. J. Mar. Res., 58, 223-268.

Tsuchiya, M., 1981: The origin of the Pacific equatorial $13^{\circ} \mathrm{C}$ Water. J. Phys. Oceanogr., 11, 794-812.

_, R. Lukas, R. Fine, E. Firing, and E. Lindstrom, 1989: Source waters of the Pacific Equatorial Undercurrent. Prog. Oceanogr., 23, 101-147.

Yeager, S. G., and W. G. Large, 2004: Late-winter generation of spiciness on subducted isopycnals. J. Phys. Oceanogr., 34, 1528-1545. 